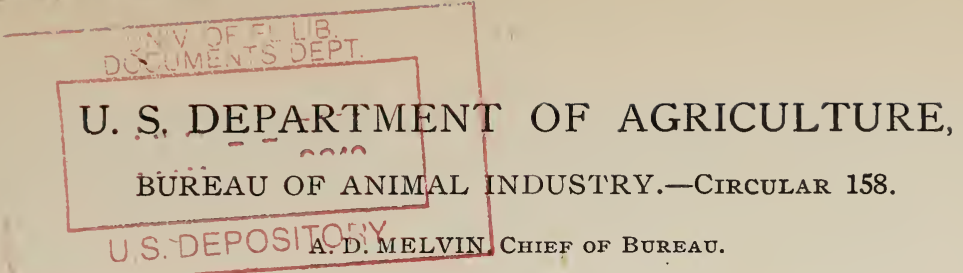

\title{
IMPROVED METHODS FOR THE PRODUCTION OF MARKET MILK BY ORDINARY DAIRIES. ${ }^{a}$
}

By C. B. Lane, Senior Dairyman, and KarL E. Parks, Architect, Dairy Division.

The object of this article is to present in a simple way the various steps in the production, handling, and distribution of market milk, particularly from the standpoint of the small producer. No attempt will be made to describe the finer points applicable to a special product such as certified milk, but the object is rather to point out practical methods adapted to the ordinary dairyman. In view of the fact that the rules and regulations pertaining to the production of milk, as formulated by boards of health, both city and State, are requiring higher standards on the part of the dairymen, it is quite important that they should know how to meet them. Many dairymen would be glad to improve if they only knew how to go about it, but frequently they have nothing to guide them.

\section{THE COWS.}

The health of the cows is essential for the production of good milk. They should be in good physical condition and free from disease. They should also be tested for tuberculosis by a capable veterinarian at least once a year, and all reacting animals removed. The object of the tuberculin test is not only to safeguard the milk supply but to protect the herd from the ravages of this disease. The feed of the herd should be wholesome, and the water supply should be protected from contamination.

Dirt and dust adhering to the cows are responsible for most of the contamination of milk. It is therefore essential that the cows be clean-not necessarily washed every day and dried with a sterile towel, but clean in a common-sense meaning-that is, free from accumulation of dirt and manure, and thoroughly brushed. If the hair on the udders, flanks, and tails is clipped, this will aid in keeping the animals clean.

THE STABLE.

The stable should be free from contaminating surroundings and well drained. It should be constructed with a view to the comfort

${ }^{a}$ Reprinted from the Twenty-fifth Annual Report of the Bureau of Animal Industry (1908). 
of the cows and to keeping it clean with as little work as possible. Ledges, etc., which collect dust should be avoided. (See fig. 3.) Details of construction will not be discussed here, as that subject is covered in another publication. (Circular 131 of the Bureau of Animal Industry.) It may be said, however, that the floors and gutters should be tight and preferably constructed of concrete. The walls and ceilings should also be tight. Some form of swing stanchion will give the cows plenty of freedom and keep them lined up on the gutter. The mangers should be low. When practicable the stalls should be constructed of metal piping (see fig. 9), exposing the

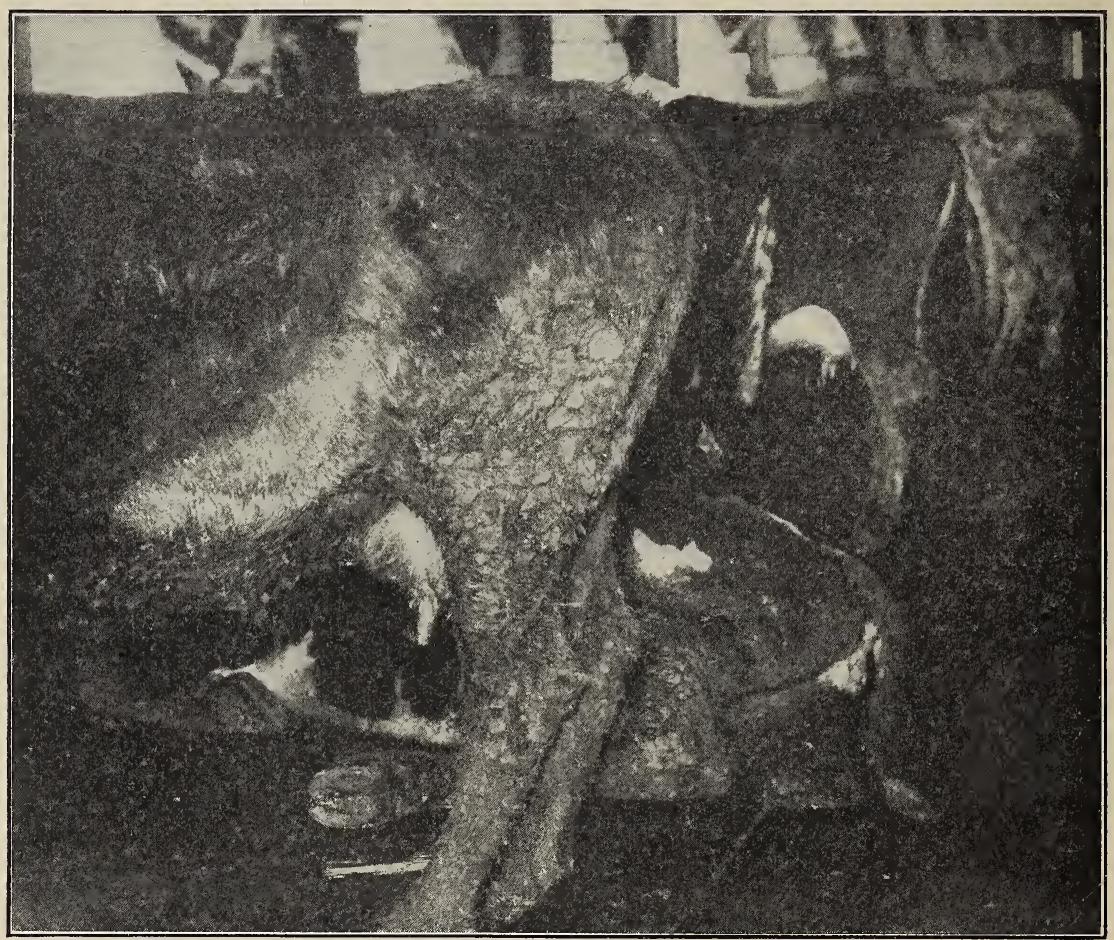

Fig. 1.-Cows in filthy condition. It is impossible to produce clean milk under such conditions.

least possible surface for collecting dust and allowing free circulation of air. An abundance of light is very important; 4 square feet of glass to each cow will be found about right. About 500 cubic feet of air space should be provided for each animal.

A system of ventilation should be provided that will keep the air fresh and pure at all.times. The King system ${ }^{a}$ has been found very satisfactory. Its essential features are several inlet flues to admit and distribute fresh air and one or more outlet flues of adequate size

\footnotetext{
$a$ The King system of ventilation is described in Bulletin 164 of the Wisconsin Agricultural Experiment Station.
} 
to assure rapid removal of foul air. Where it is not practicable to install the King system, the muslin-curtain system will be of some benefit. This consists of pieces of muslin nailed over openings in the walls at suitable places. The grade of muslin known as "Four and one-half " is about the right quality. Adjustable windows are better than no ventilation.

The most common defect in dairy stables is lack of cleanliness. Cobwebs and manure on walls and ceiling are met with in every section of the country. The dairyman should see to it that this criticism can not be made of his stable. A coat of whitewash twice a year will

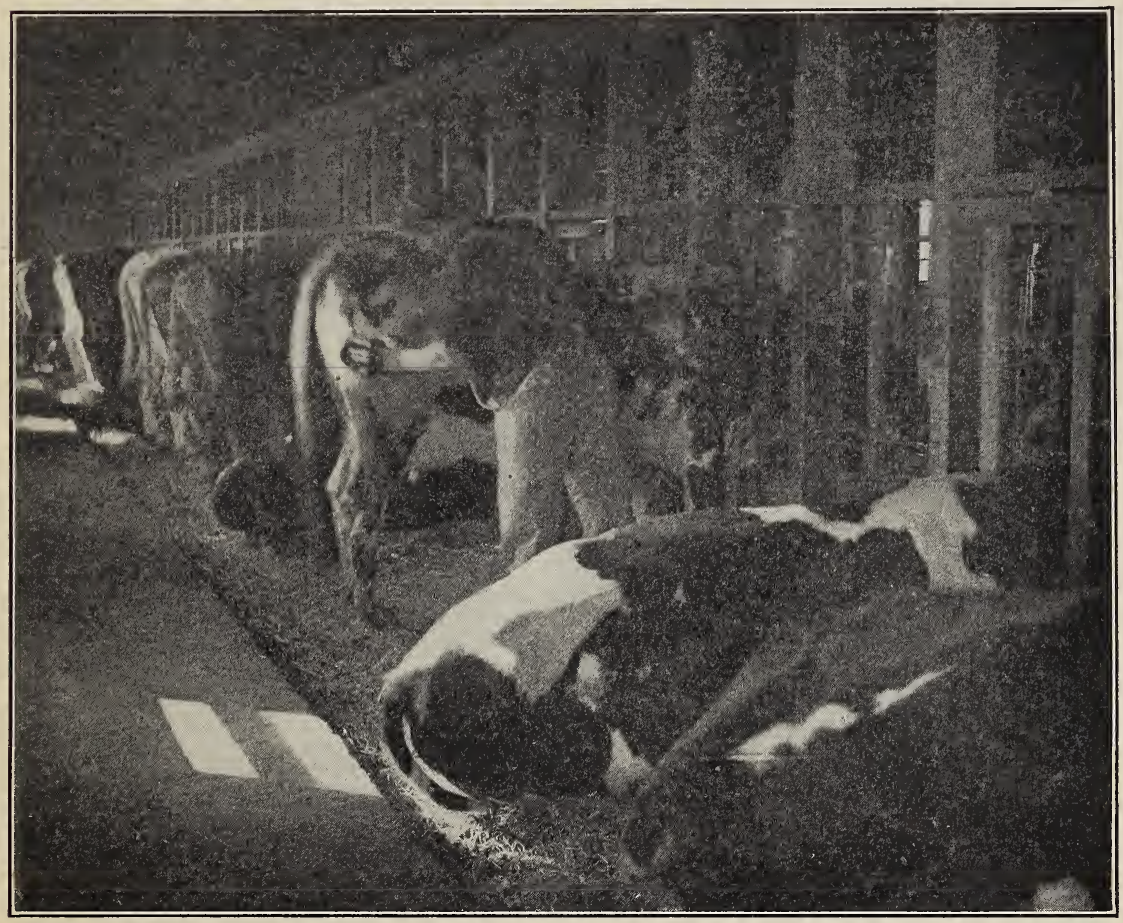

Fig. 2.-Clean cows in a clean, comfortable stable. The cows are supplied with plenty of bedding.

make the stable lighter and the air sweeter and will destroy countless germs. No other animals than the cows should be allowed in the stable. The barnyard should be well drained and free from manure and rubbish. The manure should be removed at least twice daily to the field or a safe distance from the barn, say, 40 or 50 feet. Manure about the stable breeds flies and gives off bad odors.

THE MILK HOUSE.

The milk house should be located at a convenient place where there is good drainage, and should be free from contaminating surround- 
ings. A cement floor is very important, and this should be extended up on the sides at least 6 inches, or, better still, to the window casings, particularly in the wash room. Light and ventilation should be provided, and the windows and doors should be screened in summer. Cleanliness is of great importance here, and the whole interior, including floor, walls, ceiling, and windows, should be kept clean.

PLAN FOR A MILK HOUSE. ${ }^{a}$

The building illustrated in figures 5 and 6 is designed to provide an inexpensive and conveniently arranged milk house for the

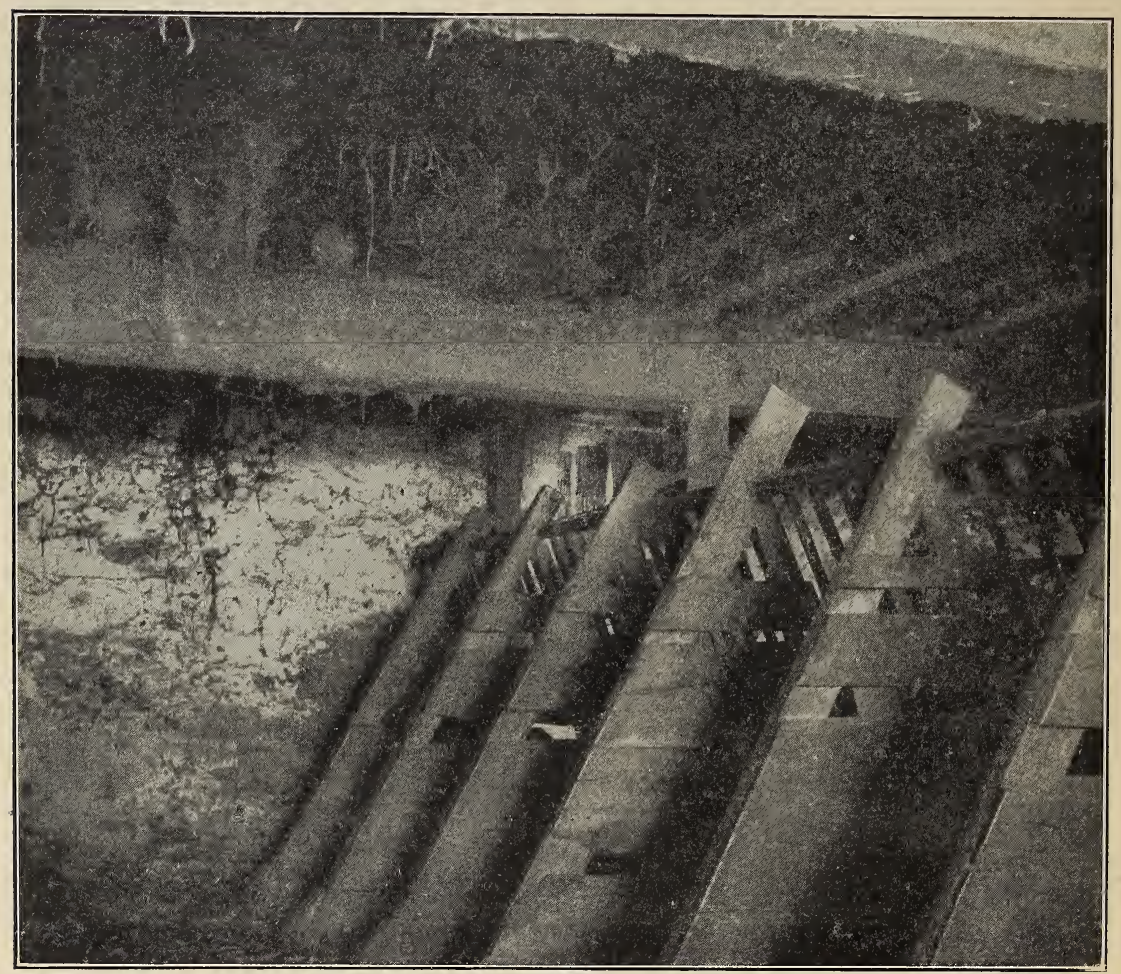

Fig. 3.-An undesirable stable. Note cobwebs heavily laden with dust, and wooden construction, which collects dirt and requires much labor to keep clean.

dairyman who produces milk for shipping or retailing from a herd of 25 to 60 cows. The building is divided into four rooms, arranged to eliminate unnecessary labor and at the same time to provide sufficient space for the apparatus, its operation and care. The best location for the milk house would be about halfway down the length of

$a$ Persons desiring to build a milk house according to this plan may obtain a blueprint showing details of construction on application to the Dairy Division, Bureau of Animal Industry, Department of Agriculture, Washington, D. C. Refer to plan $\mathbf{H}-\mathbf{2}$. 
the barn and 12 to 15 feet distant from it. $\mathrm{A}$ door in the side of the barn at this point, opening from a cross alley, makes it convenient for the milkers and saves unnecessary time and travel. A driveway should be placed between barn and milk house for bringing empty cans, bottles, fuel, ice, etc., to the milk house, and for loading milk upon the delivery wagon.

In one corner of the building a small weigh room is partitioned off, the floor of which is raised 24 inches above the main floor; this room is entered from the vestibule. The milker takes the milk of each cow to this room, where it is weighed, recorded on the milk sheet,

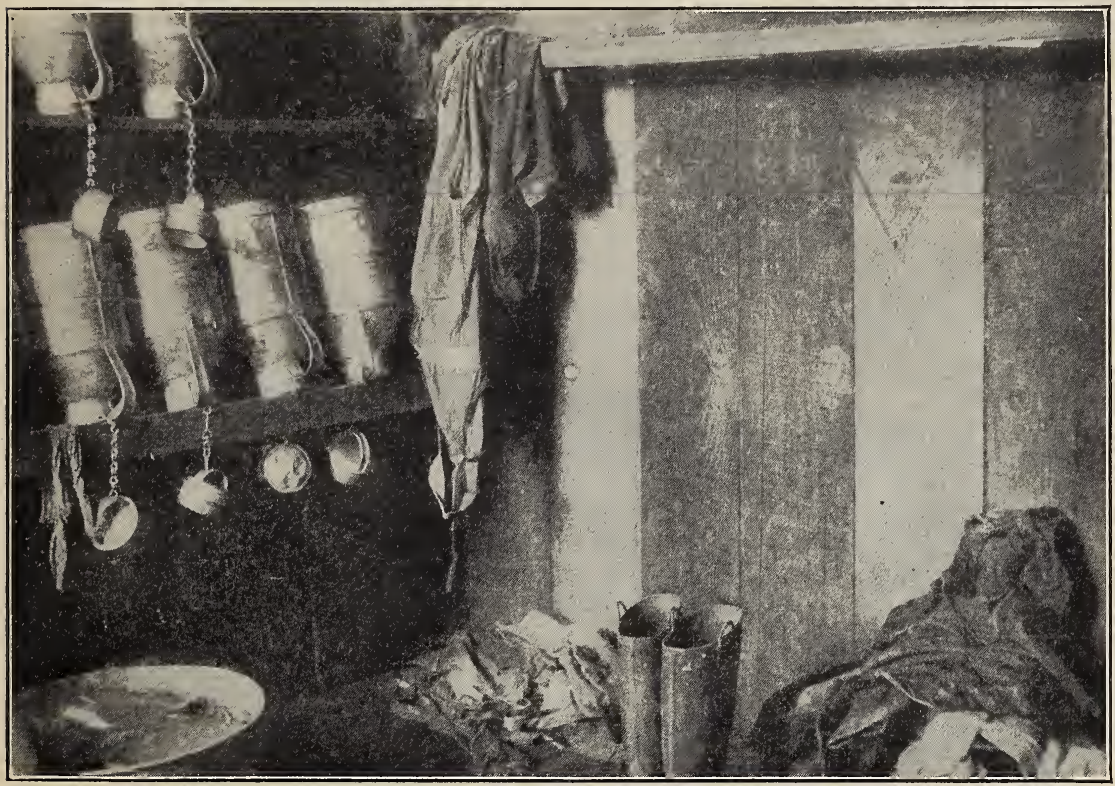

Fig. 4.-An insanitary milk room. The family washing is being done in the same tubs in which the milk cans and utensils are washed. Part of the clothes are hanging on the milk-can rack to dry, and piles of soiled clothes, boots, shoes, etc., are scattered around the floor. These conditions favor the spread of contagious diseases through milk.

and emptied through the funnel (A), which is provided with cheesecloth strainers and a hinged cover. The milk passes from the funnel by gravity to a mixing tank and cooler (B), from which it empties into a can which is carried over to the bottle filler (C) for immediate bottling, or into shipping cans which may be placed in the pool built into the bottom of a refrigerator (E). If it is desired to separate the cream, a steam turbine separator would be provided at $\mathrm{N}$, run by steam from the boiler. It will be observed that the milk room is so located that it is not necessary to enter it except to care for the milk, thus making it easy to keep clean and cool and free from flies, dust, and other contamination. 
The bottled and canned milk is placed in the refrigerator (D) until time for shipment, when it is loaded from the vestibule to the wagon. The refrigerator is built into the building, with ice storage overhead, which is filled through a door from the outside, directly from the wagon. The pool in the floor is supplied with spring water by a ram or other means, and is provided with an overflow to maintain a certain height of water. The melting ice drips into the pool, which also tends to keep the temperature of the water low.

A door from the rear gives access to the boiler room and the wash room, and through this door empty bottles and cans are returned from the wagon for cleansing. The wash room is provided with a

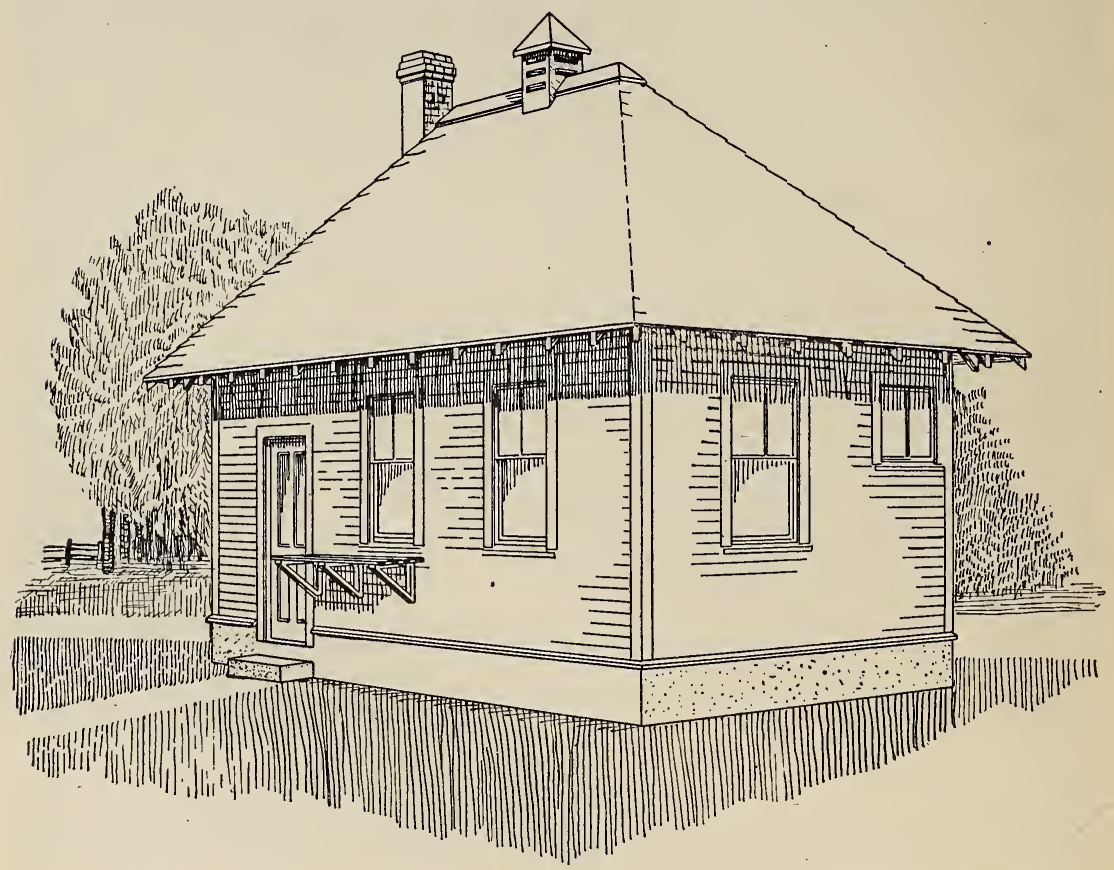

FIG. 5. - A practical and inexpensive milk house for a dairy of 25 to 60 cows.

two-compartment concrete sink, the larger compartment (I) for washing cans and bottles with soapy water, and the smaller $(\mathrm{H})$ having a revolving brush for brushing and rinsing the bottles in clear water. After the bottles are washed they are placed in galvanized iron bottle carriers in an inverted position and the carriers are placed in the sterilizer (F) on runs provided for them. The sterilizer as shown (fig. 7) will hold 240 1-quart bottles. Below the bottles in the sterilizer is a space for sterilizing cans, pails, and other apparatus, so that all may be sterilized at one time and left in the sterilizer until they are to be used, which keeps them sterile and free from contamination. Sterilization is accomplished by turning in 
steam for not less than thirty minutes (low pressure). A door from the sterilizer to the milk room is provided so that the bottles may be conveniently taken from the sterilizer and placed on the bottlefiller table for filling.

The wash room also has an outside door, giving access to a sunning rack for sunning pails, cans, etc. There should be no driveway in front of the building, as this causes a great deal of dust and dirt, which blows over the sunning rack and in at the windows and doors. In the wash room is also provided a table and a Babcock tester $(G)$ for testing samples of milk. The boiler room contains a small farm boiler which provides steam for sterilizer, separator, and bottle filler and hot water for sinks.

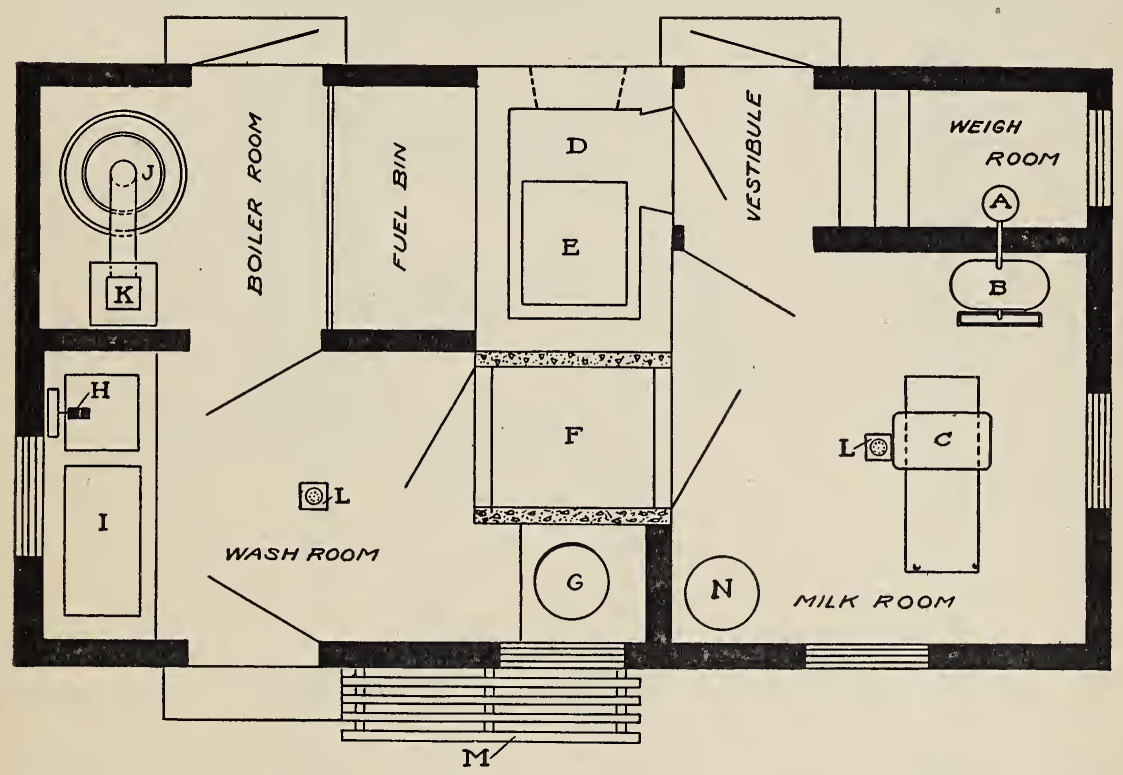

FIG. 6.-Floor plan of milk house shown in Fig. 5. $A$, receiving funnel; $B$, milk cooler ; $C$, bottle filler ; $D$, refrigerator ; $E$, cooling tank; $F$, sterilizer ; $G$, Babcock tester ; $H$, bottle washer; $I$, concrete sink; $J$, boiler; $K$, chimney; $L$, floor drains; $M$, sunning rack; $N$, separator.

If it is desired to cool the refrigerator with a brine tank a small engine and ice machine could be placed in the space allowed on the plan for a fuel bin, with condenser placed on the refrigerator wall, and fuel bin built just outside boiler-room door.

The building itself is 12 by 22 feet outside the frame, and height of story is 11 feet 2 inches in the clear. It is a light frame structure placed on a concrete foundation built 18 inches above ground, and has a concrete floor 6 inches below top of foundation wall. This brings the sills above the floor, so they will not rot from the dampness, as the floors should be washed daily. 
The exterior of the building is covered with weatherboarding, boards and battens, or roofing paper, as desired, while the interior is plastered in weigh room, milk room, and wash room with cement plaster on metal lathing and finished in white enamel paint. The walls are plastered against door and window frames, and casings omitted. All corners are plastered round and smooth to avoid lodging places for dirt and germs. Ventilator flues from the ceiling of milk and wash rooms are connected with the monitor on the roof. The boiler room is left unfinished except on wash-room partition, which is sheathed to protect plaster on wash-room side.

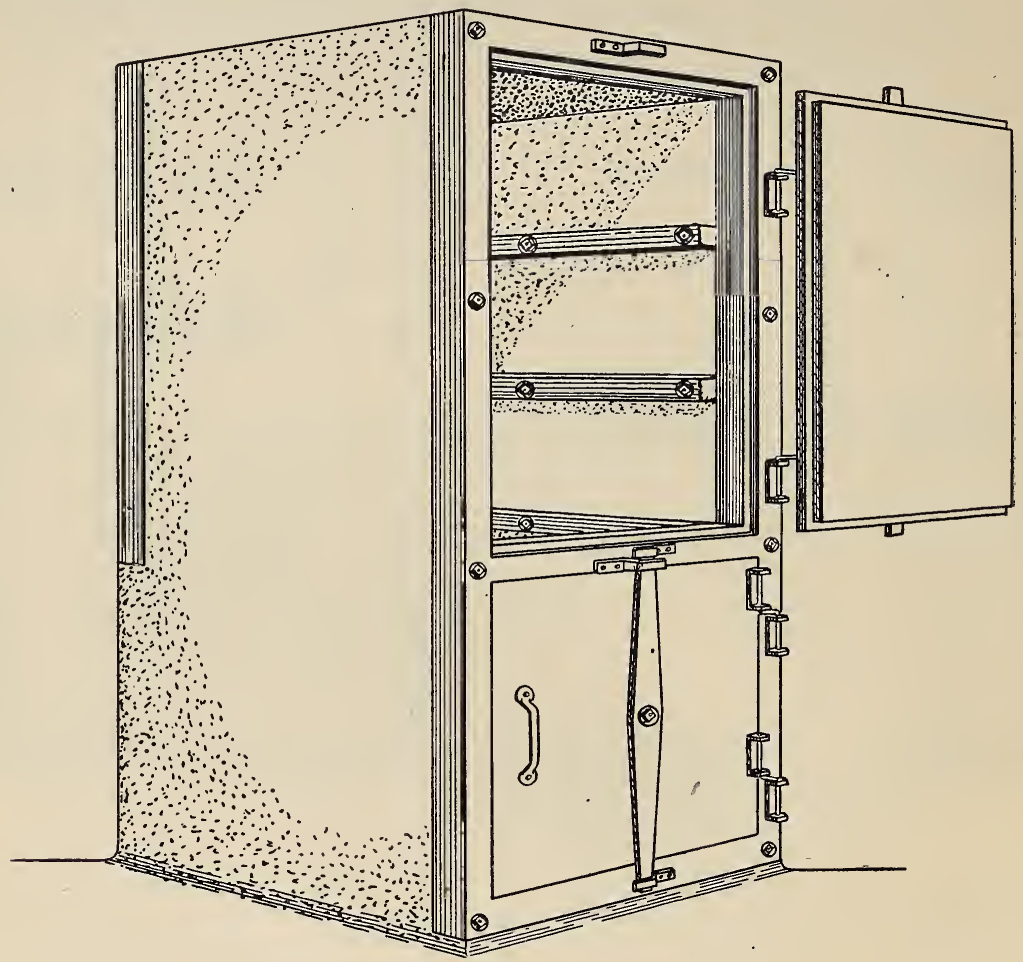

Fig. 7.-Sterilizer for milk bottles, cans, etc.

The building should be built for from $\$ 200$ to $\$ 400$, according to location, cost of material, labor, etc.

\section{UTENSILS AND EQUIPMENT.}

The utensils are a very important part of the dairyman's equipment. The cans and pails should be well built, with seams well flushed with solder, or, better still, no seams at all. All utensils require the most careful attention in regard to cleaning and sterilizing. They should be thoroughly washed and subjected to live steam or boiling water, then inverted in pure air. The kitchen stove rarely 
answers the purpose for heating water for the reason that the amount so heated is usually limited, and by the time it is taken to the place where the washing is done it has become too cool to have any effect as a sterilizing agent. A large hot-water tank or a boiler is necessary for the purpose. It is important that the water used in cleaning be pure, as contagious diseases have frequently originated from water used in washing.

Some form of small-top or covered milk pail is very important in milking (see figs. 8 and 11). Figure 8 illustrates the advantage of the covered pail over the ordinary open pail in keeping dirt out of the milk. W. A. Stocking, jr., made tests with open and covered pails in a stable where but little care was given to cleanliness, and found that milk drawn in the open pail contained an average of
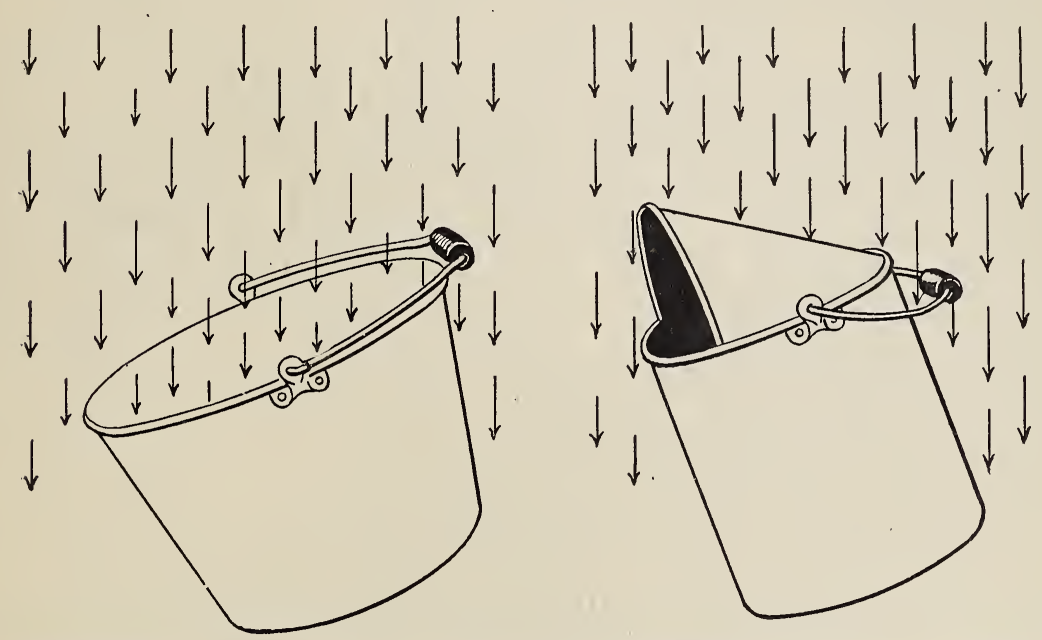

FIG. 8.-Two kinds of milk pails. The open pail admits much dirt; the covered pail keeps it out.

$3,439,200$ bacteria per cubic centimeter, while that drawn in the covered pail contained an average of only 103,600 .

A metal stool for milking is more desirable than a wooden one. It is less cumbersome and far more sanitary.

A milk cooler is another important part of the dairyman's equipment, unless the milk is drawn directly into the shipping can (as in fig. 11). The cooler must be kept clean and not located near the stable.

A cheap but practical sterilizer for a small dairyman is shown in figure 7. It is constructed of concrete, reenforced with metal lathing, and fitted with wooden doors lined with galvanized iron. The open door shows the runs on which the carriers are placed. Each space accommodates 5 carriers holding 16 one-quart bottles each. This sterilizer will cost from $\$ 30$ to $\$ 50$, depending upon the price of material and labor. 


\section{MILKING.}

The milker should prepare himself for milking to the extent of putting on a special suit or outer garment. A big apron used by some dairymen is better than nothing. The milk should be drawn with clean, dry hands. The cows having previously been cleaned, the udders and flanks should be wiped with a moist cloth preparatory to milking, or, better still, washed and thoroughly dried.

In experiments made by Stocking, only 716 bacteria pèr cubic centimeter were found in milk drawn after udders and flanks of cows had been wiped with a damp cloth, while 7,058 bacteria per cubic

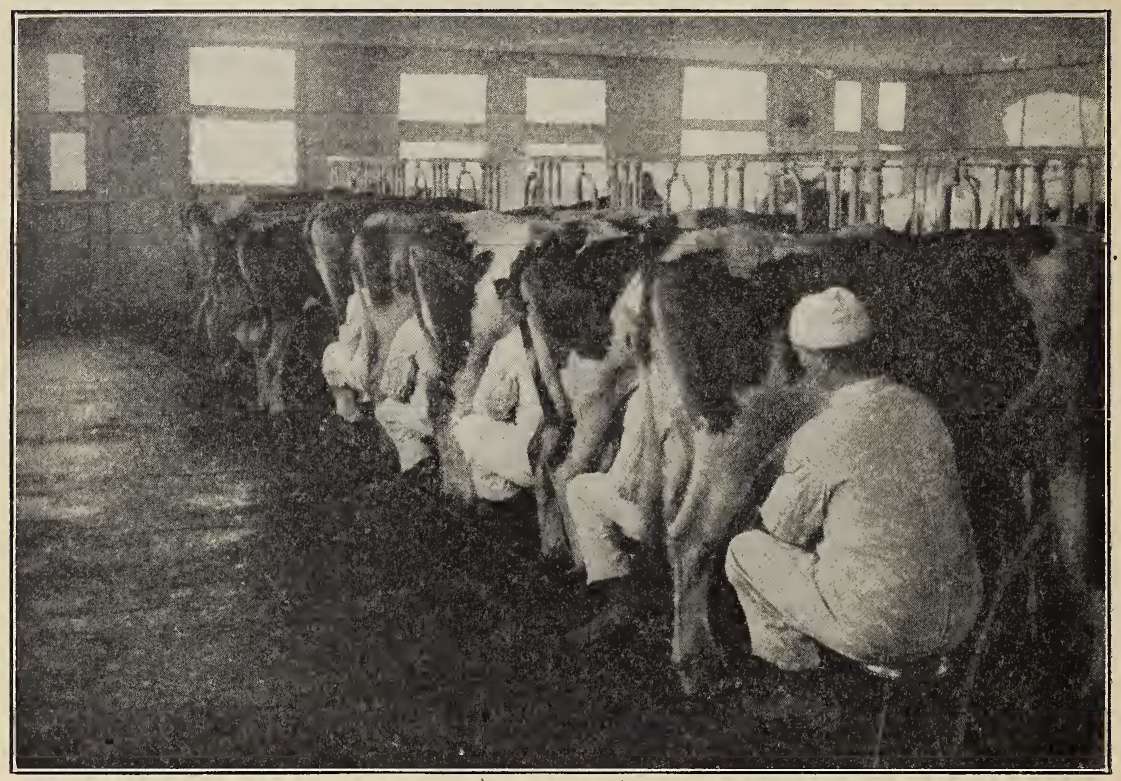

FIG. 9.-Milking cows under clean and sanitary conditions.

centimeter were found in milk from cows not so wiped before milking.

It is important that the air in the stable be free from dust and odors during milking.

\section{HANDLING THE MILK.}

The milk should be removed from the stable after each cow is milked, and cooled immediately to a temperature below $50^{\circ} \mathrm{F}$., if possible. If not convenient to cool the milk until a can is filled, it should at least be removed from the stable and not allowed to stand exposed to the stable air. The quicker it is cooled the longer it will keep sweet.

The importance of promptly cooling milk is well shown by figure 10, based on experiment by Prof. H. W. Conn, of the Storrs (Connecticut) Agricultural Experiment Station. It appears that the 
multiplication of bacteria in twenty-four hours in milk kept at $50^{\circ} \mathrm{F}$. was only fivefold, while at $70^{\circ} \mathrm{F}$. it was seven hundred and fifty fold.

The steps in handling the milk, as already given in connection with the description of a milk house, may be summarized as follows: The milk is taken up into the weigh room and poured into the strainer (A), through which it passes into the mixing tank, then falls by gravity over the cooler (B) and is transferred to the bottle filler

(C). After being bottled it is stored in the refrigerator (D), or, if held in cans, it is stored in the $\operatorname{tank}(\mathrm{E})$.

\section{STORAGE AND TRANS- PORTATION.}

Milk should be stored preferably at a temperature below $50^{\circ} \mathrm{F}$. This means that ice should be used. Spring water at a temperature not exceeding $55^{\circ} \mathrm{F}$. will give fairly good results, provided the cooling is done immedi-

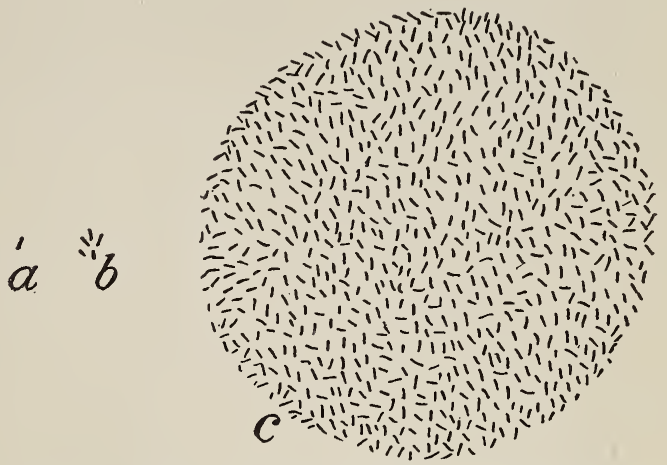

FIG. 10.-Effect of temperature upon growth of bacteria. $a$, A single bacterium; $b$, its progeny in twenty-four hours in milk kept at $50^{\circ} \mathrm{F}$. ( 5 bacteria) ; $c$, its progeny in twenty-four hours in milk kept at $70^{\circ} \mathrm{F}$. (750 bacteria). (From Bulletin 26, Storrs (Conn.) Agricultural Experiment Station.) ately and there is a good flow of water in the spring where the milk is stored. It is desirable to use cracked ice in transporting the milk in summer, either on the retail wàgon or to the station for shipment. If this is impossible, a jacket or wet blanket over the cans will aid in keeping the milk cool.

\section{A DEVICE FOR MILKING DIRECTLY INTO THE SHIPPING CAN.}

The every-day work of the dairyman should be made as simple as possible. The fewer the operations the less work and the less danger of contamination. Realizing the importance of saving time in dairy work, Dr. Lee H. P. Maynard, of the Dairy Division, has devised a combination milk pail, can, strainer, and stool (see fig. 11) ${ }^{a}$ This plan does away with the milk cooler that is usually considered a necessity in the dairy. A funnel is placed in an opening made in the shoulder of a 5-gallon can, of the type that has a cover which screws in air-tight; a piece of cheesecloth is held in the funnel by means of a metal spring, and the milk can slides into a metal frame which is

${ }^{a}$ Application has been made for United States patent on this device under the act of Congress of March 3, 1883, so that the device may be used by the Government of the United States, or any of its officers or employees in the prosecution of work for the United States, or by any person in the United States, without the payment of royalty. 
used as a stool and so constructed that the can may be adjusted to any height to suit the convenience of the milker. When the can is full all the milker has to do is to remove the funnel, screw a cap into the opening, and place the can in the storage tank. The funnel is simply washed and boiled and set away in a tin receptacle kept specially for the purpose. It is all the apparatus the dairyman has to clean if

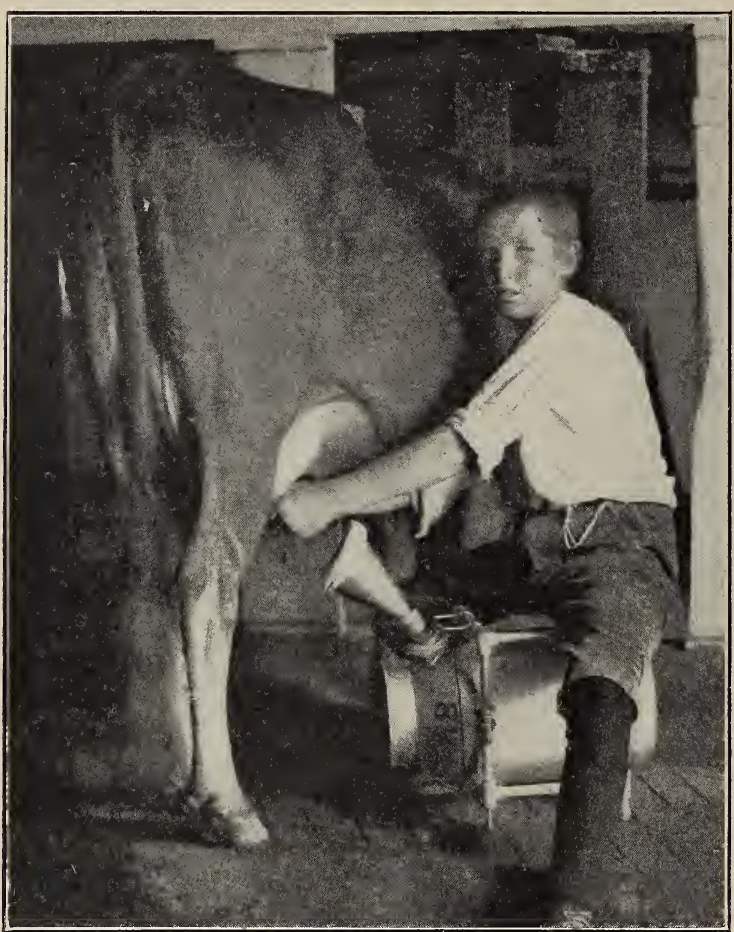

FIG. 11.-The Maynard combination milk pail, can, strainer, and stool. This simple device makes it possible to produce clean milk in almost any stable. the cans are properly sterilized by the dealer. When we compare this simple apparatus with the ordinary open milk pail and wire-gauze strainer, w o o d e n milk stool, a milk cooler (which as ordinarily kept inoculates the milk with countless bacteria), and a 10 -gallon can, we find the handling of milk much simplified.

We do not wish to give the impression that the cooling and aerating of milk as ordinarily practiced is not important, since it is well known that the keeping quality of such milk is much improved by running it promptly over a tubular cooler, provided the cooler and surrounding air are clean. Where the Maynard pail is used, however, cooling and aerating by means of a tubular cooler are not necessary, for the reason that there are but few germs to multiply and no cow-stable odors to be removed; hence cooling in the shipping can answers all requirements and is much simpler and quicker. 